\title{
Linking ethical leadership to employee performance: The roles of leader-member exchange, self-efficacy, and organizational identification.
}

1. Fred O. Walumbwa ${ }^{\mathrm{a}} *$

2. David M. Mayer ${ }^{\text {b, }}$

3. Peng Wang ${ }^{\mathrm{c}}$,

4. Hui Wang ${ }^{\mathrm{d}}$,

5. Kristina Workman ${ }^{\mathrm{b}}$,

6. Amanda L. Christensen ${ }^{\mathrm{a}}$,

${ }^{a}$ W.P. Carey School of Business, Arizona State University, Tempe, AZ 85287-4006, USA

${ }^{\mathrm{b}}$ Department of Management and Organizations, University of Michigan, USA

${ }^{\mathrm{c}}$ Farmer School of Business, Miami University, USA

${ }^{\mathrm{d}}$ Guanghua School of Management, Peking University, China

*corresponding author 


\begin{abstract}
This research investigated the link between ethical leadership and performance using data from the People's Republic of China. Consistent with social exchange, social learning, and social identity theories, we examined leader-member exchange (LMX), self-efficacy, and organizational identification as mediators of the ethical leadership to performance relationship. Results from 72 supervisors and 201 immediate direct reports revealed that ethical leadership was positively and significantly related to employee performance as rated by their immediate supervisors and that this relationship was fully mediated by LMX, self-efficacy, and organizational identification, controlling for procedural fairness. We discuss implications of our findings for theory and practice.
\end{abstract}

Keywords: ethical leadership, leader-member exchange, self-efficacy, organizational identification, performance 


\section{Introduction}

Ethical leadership is defined as "the demonstration of normatively appropriate conduct through personal actions and interpersonal relationships, and the promotion of such conduct to followers through two-way communication, reinforcement, and decision-making" (Brown, Treviño, \& Harrison, 2005, p. 120). In proposing the theory of ethical leadership, Brown et al. (2005) suggested that ethical leadership behavior plays an important role in promoting enhanced employee attitudes and behaviors. In support, prior work has linked ethical leadership to prosocial and negatively deviant behaviors (e.g., Avey et al., 2010, Brown et al., 2005, Mayer et al., in press, Mayer et al., 2009 and Walumbwa and Schaubroeck, 2009).

However, relatively few studies have tested how and why ethical leadership relates to task performance, and if so, the mechanisms through which ethical leadership relates to task performance. An important exception is recent research by Piccolo, Greenbaum, Den Hartog, and Folger (2010) that examined the roles of task significance, autonomy, and effort in the relationship between ethical leadership and task performance. Piccolo et al. (2010) found that ethical leadership increases task significance, which, in turn, results in improved performance. Accordingly, the primary goal of the present research is to extend this early and more recent research by examining the role of leader-member exchange (LMX) as a social exchange process, self-efficacy as a social learning process, and organizational identification as a social identity process in the ethical leadershipperformance relationship.

Leader-member exchange is defined as the quality of exchange between a supervisor and an employee ( Graen \& Scandura, 1987). These exchanges are posited to fall along a continuum. For example, leaders may form high-quality social exchanges that are based on trust, open communication, information sharing, and liking of followers, whereas with others, they may form lower-quality, economic exchanges that do not extend beyond the employment contract ( Erdogan et al., 2006 and Sparrowe and Liden, 1997). Self-efficacy is defined as individuals' perceptions of their ability to execute a specific task and is a major component of social learning theory ( Bandura, 1977, Bandura, 1986 and Bandura, 1997). Organizational identification refers to a feeling of oneness or belongingness to a particular group or institution ( Smidts et al., 2001, van Knippenberg et al., 2004, van Knippenberg et al., 2002 and van Knippenberg and van Schie, 2000), and is derived primarily from social identity theory (Tajfel, 1981). Together, we argue that the reason why ethical leadership predicts performance is that ethical leadership behavior enhances high-quality LMX, employees' self-efficacy, and identification with the organization. In turn, high-quality LMX, self-efficacy, and organizational identification improve employee performance.

Our contribution is to further increase understanding of the complex relationship between ethical leadership and employee performance by drawing on three major traditions in testing mediation in leadership 
research. We view identification and self-efficacy as representing two major themes in self and identity (i.e., selfconstrual and self-evaluation) perspectives as mediators. Additionally, LMX represents both the social exchange and trust perspectives as psychological states that mediate the ethical leadership effect on follower performance. Until now, the ethical leadership literature focused solely on social learning and social exchange explanations for the effects of ethical leadership. Thus, we contribute to the ethical leadership literature by integrating social identity theory and including organizational identification in our theoretical model. However, some research regarding social exchange and social identity suggests that LMX and identification may not be independent influences. For example, Sluss, Klimchak, and Holmes (2008) argued that LMX and perceived organizational support are precursors to identification, suggesting that identification mediates the influence of LMX. Similarly, van Knippenberg, van Dick, and Tavares (2007; see also Hogg et al., 2005) argued that identification and LMX may interact in predicting performance. Specifically, van Knippenberg et al. (2007) found that supervisor and organizational support interact with identification such that social exchange becomes less important with higher identification. However, to our knowledge, we are aware of no prior research that has simultaneously tested these perspectives to explain the influence of leadership on employee performance. Building on and extending the above research, we believe it is worthwhile to draw from the distinct advantages of each perspective to provide a more comprehensive understanding of the underlying mechanisms that link ethical leadership to follower performance.

Attention to the mediating mechanisms in the ethical leadership-follower performance relationship also highlights important practical benefits. For example, if research can specify the proximal processes through which ethical leadership works to increase performance, it could provide organizations with a framework to enhance performance through ethical leadership training. Finally, research on ethical leadership has not been conducted in China. Considering its rapid industrialization and the increased diversity in values held by Chinese people (Xie, Schaubroeck, \& Lam, 2008), China provides an ideal setting for extending ethical leadership research and its practical utility.

\section{Theoretical background and hypotheses}

Brown and Treviño (2006a) suggested that social exchange theory (SET; Blau, 1964) and social learning theory (SLT; Bandura, 1977 and Bandura, 1986) provide theoretical explanations for the relationship between ethical leadership and follower behaviors. Brown and colleagues (2005) suggested that followers of ethical leaders are more likely to perceive themselves as being in a social exchange relationship with their leaders because of the ethical treatment they receive and because of the trust they feel. When employees perceive that their leaders have their best interests at heart and are caring, they are likely to reciprocate by improving task 
performance. Similarly, a social learning perspective on ethical leadership proposes that ethical leaders are likely to influence followers' self-efficacy because they are attractive and legitimate role models that seek to help employees reach their potential at work (Bandura, 1986 and Bandura, 1997).

Although social exchange and social learning theories are valuable, we argue that they are not enough to explain the complex relationship between ethical leadership and followers' performance. Social identity theory (e.g., Ashforth and Mael, 1989 and Tajfel, 1981) is another intermediate theory that we believe might further help explain the relationship between ethical leadership and performance. Social identity constitutes the perception of oneness with, or belongingness to, a specific social category where individuals are intrinsically motivated to contribute to the collective good (Ashforth and Mael, 1989, De Cremer and van Knippenberg, 2003, van Knippenberg and Hogg, 2001 and van Knippenberg et al., 2004). Thus, social identity theory may complement both social exchange and social learning theories in explaining the link between ethical leadership and performance. We suggest that ethical leaders are likely to influence follower performance by enhancing greater identification with the group or organization, because such leaders represent the high ethical standards and values of the organization (van Knippenberg et al., 2004). Below, we develop hypotheses for the mediating roles of LMX, self-efficacy, and organizational identification in the ethical leadership-employee performance relationship.

\section{Ethical leadership and leader-member exchange}

Leader-member exchange (LMX) theory has received considerable attention in the organizational sciences (Nahrgang et al., 2009 and Walumbwa et al., in press). Leader-member exchange is based on the degree of emotional support and exchange of valued resources (Liden et al., 1997 and Sparrowe and Liden, 1997) between a supervisor and his or her direct report. Thus, LMX is a social exchange relationship between an employee and his or her immediate manager or supervisor (Masterson, Lewis, Goldman, \& Taylor, 2000). According to social exchange theory, employees tend to develop high-quality relationships based upon whom they interact with, how they interact with them, and their experiences with them ( Blau, 1964, Coyle-Shapiro and Conway, 2004 and Cropanzano and Mitchell, 2005). In other words, the more frequently employees interact with their immediate supervisors, the more likely the relationship will be stronger (Dienesch \& Liden, 1986). This makes leadership an important currency in social exchanges (Cropanzano and Mitchell, 2005, Erdogan et al., 2006 and Wayne et al., 2002). Therefore, we argue that because LMX relationships are developed through a series of interactions or exchanges between leaders and followers, immediate supervisors are critical in enhancing the LMX relationship because of their proximity to employees.

There are a number of ways ethical leaders can enhance high-quality LMX with their followers. First, ethical leaders are viewed as moral persons who are honest and trustworthy; they are also seen as principled 
decision makers who care more about the greater good of employees, the organization, and society (Brown and Treviño, 2006a, Brown et al., 2005 and Treviño et al., 2003). When employees perceive that leaders act in their best interests and are caring, employees infer that leaders are committed to them. The result is enhanced highquality LMX because of high levels of loyalty, emotional connections, and mutual support (Erdogan et al., 2006 and Wayne et al., 2002).

In particular, Treviño, Weaver, and Reynolds (2006) argued that, "Because ethical leaders are caring....relationships with ethical leaders are built upon social exchange and norms of reciprocity” (p. 967). Ethical leaders inform their followers of the benefits of ethical behavior and the cost of inappropriate behavior and then use balanced punishment to hold followers accountable (Brown et al., 2005). Such leaders are also more concerned with establishing trusting relationships with followers through solicitation of employees' ideas without any form of self-censorship (Brown and Treviño, 2006a and Brown et al., 2005). As a result, ethical leaders are able to develop meaningful interpersonal relationships that go beyond specified economic exchange agreements by encouraging employees' opinions (Brown and Treviño, 2006a and Walumbwa and Schaubroeck, 2009), thereby facilitating high-quality LMX. Thus, we expect a positive relationship between ethical leadership and LMX.

\section{Hypothesis 1.}

\section{Ethical leadership is positively related to leader-member exchange.}

\section{Ethical leadership and self-efficacy.}

Bandura, 1977 and Bandura, 1986 listed four techniques for enhancing self-efficacy, that is, vicarious experience or modeling, verbal persuasion, affective or physiological arousal, and enactive mastery or personal attainments; each can be influenced by ethical leadership through social learning. According to social learning theory (Bandura, 1977), individuals learn standards of behavior vicariously (i.e., by watching others) and through direct modeling and verbal persuasion, helping employees to become more confident in their abilities and strengthening their behavioral and motivational patterns. De Hoogh and Den Hartog (2008) argued that ethical leaders not only stress moral values in their decision making, but they also clarify to followers how their tasks and efforts will contribute to the achievement of important work unit goals. In addition, because ethical leaders ask "What is the right thing to do?" when making decisions, employees learn to think strategically about the decisions they make and this process enhances employee self-efficacy. By helping employees think through the decisions they make, ethical leaders help foster an important skill that employees can utilize when making decisions on their own - and this increased autonomy improves their self-efficacy beliefs. 
Similarly, Zhu, May, and Avolio (2004) argued that ethical leaders' benevolent behavior and consideration of employees' developmental needs should cause such leaders to place employees in situations that facilitate growth and confidence in their job-related skills, thereby enhancing their levels of self-efficacy through observational or vicarious learning and persuasion. Bandura makes similar arguments. Specifically, drawing from social cognitive theory of agentic and self-regulation perspectives, Bandura, 1991 and Bandura, 1999 has argued that social factors such as leadership, more so when such leaders are credible and demonstrate moral conduct, play a critical role in developing and strengthening efficacy beliefs.

There is some empirical support for these arguments. For example, Eden and associates (e.g., Eden and Aviram, 1993 and Eden and Kinnar, 1991) demonstrated that credible sources of feedback, as we would expect with ethical leaders (Brown et al., 2005), can indeed raise self-efficacy. In addition, several ethical leadership researchers (e.g., Detert and Treviño, 2010, Detert et al., 2007, Mayer et al., 2009 and Walumbwa and Schaubroeck, 2009) have argued that ethical leadership exerts its effects in large measure through modeling, which is seen as an educational tool. In other words, employees learn how to best perform their jobs by watching their managers (Mitchell \& Palmer, 2010), thereby enhancing general perceptions of self-efficacy.

Ethical leaders can also enhance followers' self-efficacy through affective arousal and enactive mastery. Ethical leaders care about more than outcomes - the process matters, too. Such leaders help employees to focus on the processes in doing their work, which helps to reduce some of the anxiety and stress of the ultimate outcome, thereby enhancing one's self-efficacy. Regarding personal attainments, ethical leaders are described as more caring about employees' best interests and thus want to see them perform well and reach their potential ( Brown et $a l ., 2005)$. Such leader behavior is more likely to create a psychologically safe environment for employees to get direct feedback regarding their enactive mastery (Walumbwa \& Schaubroeck, 2009). The result is feeling more confident in one's ability, leading to increased self-efficacy. Based on the above arguments and empirical evidence, we expect a positive relationship between ethical leadership and general perceptions of self-efficacy.

\section{Hypothesis 2.}

\section{Ethical leadership is positively related to follower perceptions of self-efficacy.}

Ethical leadership and organizational identification.

At the conceptual level, leader behaviors that are seen as more trusting should promote and raise identification with the workgroup or organization, because such interpersonal treatment conveys to individuals that they are valued and respected (Tyler, 1997). Specifically, because ethical leaders are proactive, we expect 
such leaders to increase cooperation (De Cremer and van Knippenberg, 2002, De Cremer and van Knippenberg, 2003 and Dukerich et al., 2002) which, in turn, should promote organizational identification. Mael and Ashforth (1992) found that identification is more likely to occur in the absence of competition within the organization. Furthermore, scholars (e.g., De Cremer and van Knippenberg, 2002, Tyler and Blader, 2000 and van Knippenberg et al., 2004) suggest that people identify more with social institutions (i.e., organizations) when trust is present, satisfying individuals' need for psychological safety. Empirical research provides support for this notion. For example, several studies, including experimental work, have shown that characteristics of ethical leaders such as openness and trustworthiness, among others, are positively related to organizational identification (see De Cremer et al., 2008, McAllister, 1995, Sluss and Ashforth, 2008 and Smith et al., 2006). Drawing on this literature, we expect a positive ethical leadership-organizational identification relationship.

\section{Hypothesis 3.}

\section{Ethical leadership is positively related to organizational identification.}

Leader-member exchange, self-efficacy, and organizational identification as mediators.

\section{Leader-member exchange.}

Social exchange theory suggests that employees who are in a high-quality LMX relationship tend to be more effective workers (Sparrowe \& Liden, 1997). This process can be explained by a core principle of social exchange theory called the 'norm of reciprocity,' which suggests that individuals who are treated favorably by others feel a sense of obligation to respond positively or return favorable treatment in some manner (Blau, 1964 and Gouldner, 1960). Once high-quality LMX is in place, subordinates tend to reciprocate by exerting effort on behalf of the leader (Wayne \& Green, 1993). As a result, high-quality LMX can boost individual motivation for high job performance (Chen \& Kanfer, 2006). Supporting these arguments, several prior individual and metaanalytic studies reported significant positive relationships between LMX and job performance (Bauer et al., 2006, Gerstner and Day, 1997, Walumbwa et al., 2009, Walumbwa et al., in press and Wang et al., 2005). These findings are important because they suggest that LMX is a proximal cause of functional workplace behavior (Gerstner and Day, 1997, Sparrowe and Liden, 1997 and Wayne et al., 2002). For example, Chen and Klimoski (2003) found in a longitudinal study that newcomers who developed a better relationship with their supervisor subsequently performed better. Therefore, we argue that LMX acts as an important mechanism through which ethical leadership influences performance. However, because there may be other processes separate from a social exchange process, such as social learning (e.g., Brown et al., 2005) and social identity, that may also mediate the effect of ethical leadership on performance, we propose partial rather than full mediation. 


\section{Hypothesis 4.}

Employee perceptions of leader-member exchange partially mediate the relationship between ethical leadership and employee performance.

\section{Self-efficacy.}

Bandura (1997) suggested that self-efficacy plays an important role in task-related performance by influencing individuals" choice, effort, and persistence. Stajkovic (2006) noted, "Having high confidence makes it more likely that people will initiate action, pursue it, and sustain persistence because they feel certain that they can handle what they desire to do or needs to be done" (p. 1209). Moreover, because they set difficult and challenging personal goals, individuals with high self-efficacy are more likely to be successful performers (Bandura and Locke, 2003 and Stajkovic, 2006). In support, a growing body of research, including ample experimental, longitudinal, and meta-analytic studies, supports the influence of self-efficacy on performance in a variety of organizational settings (e.g., Bandura and Locke, 2003, Chen et al., 2001, Walumbwa et al., 2008, Walumbwa et al., 2009 and Walumbwa et al., in press). In particular, a meta-analysis of 114 studies by Stajkovic and Luthans (1998) revealed that self-efficacy was positively correlated with work-related performance $(\mathrm{r}=.38)$.

Although evidence for self-efficacy as a potential mediator in the ethical leadership-performance relationship is limited, we invoke social learning theory (Bandura, 1977 and Bandura, 1986) to explain why ethical leadership may affect performance through self-efficacy. Social learning theory suggests that leader behavior is likely to serve as an exemplary guide to followers' behavior through role modeling. According to Bandura, 1977, Bandura, 1986 and Bandura, 1997, role modeling, especially when leaders are more attractive and credible, is important for effective task performance. Thus, leadership affects follower performance because leaders serve as role models through whom followers can expand their knowledge by learning and acquiring new skills to improve their performance. Therefore, we expect self-efficacy to act as a mediator for the relationship between ethical leadership and performance. Consistent with Hypothesis 4 above, we expect the mediation to be partial.

\section{Hypothesis 5.}

Employee perceptions of self-efficacy partially mediate the relationship between ethical leadership and employee performance. 


\section{Organizational identification}

The literature on identification is vast (see van Knippenberg et al., 2004, for a review). Generally speaking, this body of research suggests that individuals with high organizational identification tend to be greater contributors to their workgroup or firm (van Knippenberg et al., 2004). This is because identification leads individuals to perceive themselves in terms of the characteristics they share with the organization (van Knippenberg \& van Schie, 2000) and to promote positive responses toward one's employing organization (Dutton, Dukerich, \& Harquail, 1994). As a result, individuals tend to expend more effort on behalf of the organization (van Knippenberg et al., 2004), and by so doing, they are more motivated to achieve goals on behalf of the organization (van Knippenberg, 2000). This heightened effort and motivation is likely to increase individual performance. Supporting these arguments, a growing body of research has shown that identification is positively related to individual behaviors such as performance (e.g., Pratt et al., 2006, Smidts et al., 2001, Walumbwa et al., 2008, Walumbwa et al., 2009 and Walumbwa et al., in press).

On the other hand, Hogg's (2001; see Hogg and van Knippenberg, 2003 and van Knippenberg et al., 2004 for reviews) social identity theory of leadership suggests that "leadership is about how some individuals or cliques have disproportionate power or influence to set agenda, define identity, and mobilize people to achieve collective goals" (p. 188). He further suggested that it is the leader's responsibility to encourage followers to engage in identification and to represent the values and identities of members. Based on the social identity theory of leadership and extant research linking identification to performance, we expect organizational identification to serve as a mediator through which ethical leadership influences performance. However, because we have argued in Hypothesis 4 and Hypothesis 5 that the influence of ethical leadership on performance may also be explained through perceptions of LMX and self-efficacy, we propose partial mediation rather than full mediation. Thus, we test the following:

\section{Hypothesis 6.}

Employee organizational identification partially mediate the relationship between ethical leadership and employee performance.

\section{Method}

\section{Participants and procedure}


We surveyed 72 supervisors and 201 immediate direct reports from a major pharmaceutical joint-venture in the People's Republic of China. The participating supervisors attended a training project offered by a major business school located in northern China. As a major pharmaceutical company in China that directly deals with ethical issues every day, this company provided a unique setting in which to study the effects of ethical leadership.

The average age of direct reports was 32 years $(\mathrm{SD}=4.9)$, and the average age of the supervisors was 37 years $(\mathrm{SD}=3.9)$. The supervisors had been with the organization on average for 8 years $(\mathrm{SD}=4.7)$, whereas the direct reports had worked with the supervisor on average for 3 years $(\mathrm{SD}=2.1)$ and were all full-time employees. Forty-four percent of the direct reports were female, and at least $94 \%$ had the equivalent of a United States (US) community college degree. Among supervisors, $53 \%$ were male, and at least $86 \%$ had the equivalent of a US community college degree.

Direct reports received a survey packet via email containing a cover letter from the researchers that was endorsed by the company's human resource department. The cover letter explained the purpose of the study, provided assurances of participant confidentiality, and informed participants that only group data would be reported to the organization. Participants completed measures of ethical leadership, LMX, self-efficacy, organizational identification, and procedural fairness and personal information including age, sex, and tenure. Each participant was assigned a unique survey code so that we could match data with supervisors' ratings. All completed surveys were returned directly back to researchers via email. We assured participants full confidentiality and all were informed in writing that their names would not be reported in the data. The response rate was approximately $78 \%$. Finally, immediate supervisors $(n=72)$ evaluated their direct reports' job performance (100\% response rate). As with employees, we also assured supervisors of confidentiality.

\section{Measures}

We translated scales that had not already been translated from English to Chinese by previous researchers for this study following Brislin's (1980) recommendations. Specifically, a bilingual speaker performed the initial translation, after which the questionnaire was given to another bilingual speaker who was asked to back-translate the same items into English without having access to the original survey. The second translator was also asked to comment on any item that was seen as ambiguous. Finally, we gave the same survey to two additional native Chinese speakers, who examined the surveys to ensure that items were interpretable in Chinese. This process did not suggest noteworthy changes in any of the items used in this study. All scales were anchored on a five-point scale ranging from (1) "strongly disagree" to (5) "strongly agree." 


\section{Ethical leadership}

We assessed ethical leadership behavior $(\alpha=.87)$ using the 10-item Ethical Leadership Scale (ELS) developed and validated by Brown et al. (2005). Sample items include, "The supervisor ... disciplines employees who violate ethical standards" and "... sets an example of how to do things the right way in terms of ethics."

\section{Leader-member exchange (LMX)}

We assessed LMX $(\alpha=.88)$ using Scandura and Graen's (1984) LMX-7 scale. Respondents indicated the extent to which they agreed with each statement. Sample items include, "My supervisor recognizes my potential" and "I have an effective working relationship with my supervisor."

\section{Self-efficacy}

We used Spreitzer's (1995) three-item measure of self-efficacy $(\alpha=.81)$. We used this measure because it is job-specific and thus relevant to our focus on task performance. Sample items include, "I am confident about my ability to do my job" and "I have mastered the skills necessary for my job."

\section{Organizational identification}

We measured organizational identification $(\alpha=.84)$ using a 5 -item scale from Smidts et al. (2001). This scale is based on social identity theory and includes both cognitive and affective elements, is reliable, and has been used in past research (Walumbwa et al., 2009). Sample items include, "I am glad to be a member of this organization" and "I feel strong ties with my organization."

\section{Employee performance}

We measured employee task performance $(\alpha=.92)$ using 11 items from Tsui, Pearce, Porter, and Tripoli (1997). Each supervisor provided ratings for their direct reports. The items cover a broad array of job performance indicators including quantity, quality, efficiency, overall ability, judgment, accuracy, job knowledge, and creativity in performing employees' assigned roles. Sample items include, “This employee strives for higher quality work than required" and "This employee's efficiency is much higher than average." 


\section{Control}

Because of conceptual and operational similarities between procedural fairness and ethical leadership, we controlled for procedural fairness to ensure that our results were not spurious and to be able to provide more confidence regarding the unique contribution of ethical leadership. Further, prior research has linked procedural fairness to LMX, self-efficacy, and performance (Smith et al., 2006, van Knippenberg and De Cremer, 2008 and Walumbwa et al., 2009).

We assessed procedural fairness $(\alpha=.89)$ using Colquitt's (2001) 7-item measure. We asked respondents to rate the degree to which the processes that their immediate supervisor uses to make decisions about evaluations, promotions, rewards, etc. are characterized by items such as, "Those procedures have been free of bias" and "I have had influence over the outcome arrived at by those procedures."

\section{Analytic strategy}

Data for this study are hierarchical in nature, because employees were nested within supervisors (each supervisor rated about 3 direct reports' job performance). Therefore, we used hierarchical linear modeling (HLM; Raudenbush \& Bryk, 2002) to test our hypotheses. To facilitate the interpretation of the HLM results, we used grand-mean centering for all of our analyses.

\section{Results}

\section{Aggregation of ethical leadership}

To address potential problems with same-source response bias, we aggregated ethical leadership to the group level to reflect group members' perceptions of the extent to which the leader demonstrated ethical leadership behavior. Theoretically, there is ample support for the idea that leadership perceptions in general, and especially perceptions about leader ethicality, are shared among employees in work units (see Brown and Treviño, 2006b, Mayer et al., 2009, Mayer et al., in press and Walumbwa and Schaubroeck, 2009 for examples). Indeed, because of social information processing, socialization, and attraction-selection processes, we expect high agreement on ethical leadership.

To support the aggregation of ethical leadership, we calculated within-group agreement (rwg; James, Demaree, \& Wolf, 1984) and two intraclass correlations: ICC1, which indicates the proportion of variance in ratings due to group membership, and ICC2, which indicates the reliability of group mean differences (Bliese, 2000). To do this, we first tested whether average scores differed significantly across groups as indicated by an F 
test from a one-way analysis of variance (ANOVA). Results showed that ethical leadership varied significantly across groups $(\mathrm{F}(71,129)=2.53, \mathrm{p}<.05)$. Using the results from the one-way ANOVA, we determined that the ICC 1 and ICC2 values were .34 and .60, respectively. The median rwg value was .86. As can be seen, the ICC2 value was lower than the recommended criteria of .70 (Bliese, Halverson, \& Schriesheim, 2002). This is because the present study's average group size of 3 was not big enough to result in a large ICC2 value; ICC2 value is a function of ICC1 and group size ( Bliese, 1998 and Bliese, 2000). However, because the ANOVA, ICC1, internal consistency, and rwg were all above acceptable cut offs, aggregation is justified (Bliese, 1998). Therefore, we proceeded to create an aggregated measure for ethical leadership, acknowledging that the relationships between the aggregated ethical leadership and the other study variables might be underestimated.

\section{Validity issues}

With the exception of performance evaluations, the measures of ethical leadership, procedural fairness, LMX, self-efficacy, and organizational identification were all collected from the same source (employees). Therefore, we conducted a series of CFAs to examine whether these variables captured distinct constructs. These tests were conducted at the individual level. To maintain favorable indicator-to-sample-size ratios, we used three randomly created parcels of items for the ethical leadership and performance constructs and two parcels of items for the procedural fairness, LMX, self-efficacy, and organizational identification constructs.

Results of the tests of competing CFA models are shown in Table 1. As shown, our results suggest that the hypothesized six-factor measurement model fit the data well $(\chi 2=79.34, \mathrm{df}=62, \mathrm{p}<.05, \mathrm{TLI}=.99, \mathrm{CFI}$ $=.99, \mathrm{RMR}=.01, \mathrm{RMSEA}=.04)$ and better than the alternative models. For example, relative to the hypothesized model, an alternative model in which indicators of ethical leadership and LMX were set to load on a single construct fit the data significantly worse $(\chi 2=177.88, \mathrm{df}=67, \Delta \chi 2[5]=98.54, \mathrm{p}<.05, \mathrm{TLI}=.88, \mathrm{CFI}$ $=.90, \mathrm{RMR}=.05, \mathrm{RMSEA}=.10$, Model 3), as did an alternative model in which indicators of LMX and selfefficacy were set to load on a single construct $(\chi 2=156.05, \mathrm{df}=67, \Delta \chi 2[5]=76.71, \mathrm{p}<.05, \mathrm{TLI}=.90, \mathrm{CFI}=.91$, $\mathrm{RMR}=.05, \mathrm{RMSEA}=.09$, Model 6 ). These results provided support for the discriminant validity of our measures.

\section{Hypotheses tests}

Table 2 presents the descriptive statistics, internal consistency reliabilities, and correlations among the study variables. Although these correlations are in the expected directions, they do not take into account the nested nature of the data. Therefore, we rely on HLM to test our hypotheses. 


\section{Hypotheses 1-3: effects of ethical leadership}

The HLM results for testing Hypothesis 1, Hypothesis 2 and Hypothesis 3 are displayed in Table 3. Before testing our hypotheses, we examined whether there was significant systematic between-group variance in supervisor-rated individual performance. Results of a null model revealed that $19 \%$ of variance in supervisorrated individual performance resided between groups, and the chi-square test was significant $(\mathrm{p}<.01)$; that is, the intercept term significantly varied across groups. As shown in Table 3, the HLM results revealed that ethical leadership significantly relates to supervisor-rated performance $(\hat{y}=.15, p<.01$; Model 1), controlling for procedural fairness. The HLM results shown in Table 3 also reveal that ethical leadership is significantly related to employee perceptions of LMX $(\hat{y}=.50, p<.01$; Model 2), self-efficacy ( $\hat{y}=.47, p<.01$; Model 3), and organizational identification $(\hat{y}=.37, p<.01$; Model 4$)$, controlling for perceptions of procedural fairness. These results provide support for Hypothesis 1, Hypothesis 2 and Hypothesis 3.

\section{Hypotheses 4-6: the mediating roles of LMX, self-efficacy, and organizational identification}

Hypothesis 4, Hypothesis 5 and Hypothesis 6 predicted that LMX (H4), self-efficacy (H5), and organizational identification (H6) would partially mediate the relationship between ethical leadership and supervisor-rated performance. We followed the four-step procedure for mediation described by Kenny, Kashy, and Bolger (1998). These results are also shown in Table 3.

In Step 1, ethical leadership needs to be significantly related to job performance. As expected, this condition was supported by the result showing a significant relationship between ethical leadership and employee performance (Model 1). Step 2 requires that ethical leadership be significantly related to LMX, self-efficacy, and organizational identification. This requirement was also supported by the results for Hypothesis 1, Hypothesis 2 and Hypothesis 3 above. Step 3 requires that LMX, self-efficacy, and organizational identification be significantly related to performance. In support of this requirement, results revealed that LMX $(\hat{y}=.21, p<.05$; Model 5), selfefficacy $(\hat{y}=.23, p<.01$; Model 5), and organizational identification $(\hat{y}=.21, p<.01$; Model 5) were significantly related to supervisor-rated performance. Finally, Step 4 requires that the ethical leadershipperformance relationship is not significant (full mediation) or the strength of the relationship between ethical leadership and performance is reduced (partial mediation) when LMX, self-efficacy, or organizational identification are included in the same model. 
To test whether LMX, self-efficacy, or organizational identification partially or fully mediate the ethical leadership-performance relationship, we ran separate HLM analyses for each mediator, controlling for procedural fairness in each model. The HLM results revealed that LMX, self-efficacy, and organizational identification were all significantly related to performance. Similarly, the effect of ethical leadership on performance remained significant. Therefore, these results provided further evidence that LMX, self-efficacy, and organizational identification each separately and partially mediated the influence of ethical leadership on performance, supporting Hypothesis 4, Hypothesis 5 and Hypothesis 6.

To further explore whether LMX, self-efficacy, and organizational identification taken together would fully mediate the influence of ethical leadership on performance, we included procedural fairness (control), ethical leadership, LMX, self-efficacy, and organizational identification in the same model and assessed the change in the coefficient of ethical leadership from Model 1. As shown in Table 3, the HLM results revealed that perceptions of employee LMX $(\hat{y}=.16, p<.01$; Model 6), self-efficacy $(\hat{y}=.18, p<.01$; Model 6), and organizational identification ( $\hat{y}=.15, \mathrm{p}<.01$; Model 6 ), the mediating variables, were significantly related to performance. However, the effect of ethical leadership on performance was no longer significant ( $\hat{y}=.08, p>.10$; Model 6). These results suggest that the influence of ethical leadership on performance is exerted through the mediating influences of LMX, self-efficacy, and organizational identification. A Sobel (1982) test confirmed that the indirect effect of ethical leadership on performance was significant (LMX: $\mathrm{z}=3.49, \mathrm{p}<.01$; self-efficacy: $\mathrm{z}=$ $3.62, \mathrm{p}<.01$; identification: $\mathrm{z}=3.29, \mathrm{p}<.01)$.

\section{Discussion}

To our knowledge, this is the first attempt to simultaneously test the role of LMX as a social exchange process, self-efficacy as a social learning process, and organizational identification as a social identity process to extend our understanding of how ethical leadership influences employee performance. Our results showed that ethical leadership was positively related to LMX, self-efficacy, and organizational identification, which, in turn, were all positively related to employee performance. The implications of our findings are discussed below.

\section{Theoretical Implications}

Our findings extend research on ethical leadership and make several important contributions to the literature. The primary contribution of our study is that we identified psychological processes by which ethical leadership relates to employee performance. Brown and colleagues (e.g., Brown and Treviño, 2006a and Brown et al., 2005) proposed that social exchange theory (Blau, 1964) and social learning theory (Bandura, 1977 and Bandura, 1986) are primary mechanisms by which ethical leaders influence their followers. Along this line, our 
study makes two important contributions. First, consistent with Brown and colleagues' theorizing, we found LMX and self-efficacy to be important intervening variables in the ethical leadership-performance relationship. Thus, we contribute to the ethical leadership literature by empirically testing the social and psychological perspectives explaining the ethical leadership-employee performance relationship. However, these two variables only partially mediated the relationship, which leads to the second important contribution. Our findings showed that social identity theory is another important mechanism that, in combination with social exchange and learning perspectives, can help explain the complex ethical leadership-employee performance relationship. Thus, our study represents the first attempt to integrate social exchange, social learning, and social identity perspectives in explaining the relationship between ethical leadership and employee performance.

For the sake of parsimony, we focused on the three mediators that we thought were most theoretically relevant, recognizing that there may be more mediating mechanisms than we examined in this research. However, we do not make the argument that all mechanisms are equal in strength but suggest certain mechanisms may be more likely for certain individuals. For example, an individual with an interdependent self-construal (Singelis, 1994) may perceive greater LMX from an ethical leader as compared to an individual who has less of a desire for social relationships. In addition, an individual who has worked at an organization for a long time and thus is committed to the organization's values may be more likely to respond to an ethical leader by feeling more identified with the organization as compared to an individual who has less of a value congruence with the organization. Also, an individual who is low on self-esteem or dispositional self-efficacy may respond to an ethical leader by feeling more efficacious in his/her work as compared to an individual high in self-esteem/selfefficacy who does not need the same level of assistance from his/her leader. These are three examples of how the three mechanisms may be more or less important depending on the characteristics of the employee. However, because ethical leadership research is still in its infancy (Mayer et al., 2009), work is needed that explicates the myriad of boundary conditions (e.g., moderators) that serve to either promote or impede the effectiveness of ethical leadership in facilitating employee performance through various mechanisms.

Moreover, this research has theoretical implications that extend beyond the ethical leadership literature. For example, this research contributes to the emerging area of research integrating leadership, self, and identity (van Knippenberg et al., 2004). Indeed, we examined how a form of leadership central to these constructs impacts self-perceptions (self-efficacy) as well as one's social identity (identification). Thus, we highlight the importance of linking leadership to employees' behaviors through mechanisms that involve the self and one's identity. In addition, although leadership scholars generally acknowledge that there are typically several mechanisms that link leader behavior to employee outcomes, leadership research tends to either not measure the theorized mediator or to measure one mediator per study (De Cremer \& van Knippenberg, 2005 is an exception). Our research highlights the value in examining multiple mediators within the same study — as this approach allows one to 
determine the relative importance of each of the mediators. We encourage leadership scholars to utilize this approach in future work.

\section{Practical implications}

Our study has several important implications for managers. First, by showing LMX, organizational identification, and self-efficacy as mediators, our results suggest that when determining how to influence employee performance, managers should consider the nature of the relationship they develop with their direct reports and how to raise employees' confidence levels. Once strong LMX, self-efficacy, and identification are achieved, employees are likely to put forth more effort, thereby enhancing their performance.

Second, our findings also suggest that ethical leadership may not only be normatively appropriate but is also instrumental for the effective functioning of organizations. Specifically, our results demonstrate that ethical leadership can have an impact not only on ethics-related outcomes, but also on performance. Thus, organizations may find it useful to emphasize both leader and follower selection and training so that ethical behaviors are exhibited by and rewarded in employees. Fortunately, successful programs already exist that can be used to train employees to act in a just manner (Cole \& Latham, 1997). Our findings suggest that this sort of approach, aimed specifically at ethical leadership principles, might increase not only employee performance, but also employee self-efficacy, leader-subordinate relationship quality, and identification with the organization.

Finally, apart from submitting that more training on ethical leadership and behavior could be helpful in general, our findings suggest ways to communicate and structure ethics initiatives. For example, our findings suggest that organizations may need to explain the benefits of strong ethics and ethical leadership in terms of performance (i.e., making the business case for ethics). We suggest this should go beyond the usual ethical training initiatives to include ethics as a core component of all leadership education and development programs.

\section{Limitations and conclusions}

The present study has some limitations. First, because employees provided ratings of ethical leadership, LMX, organizational identification, and self-efficacy, the hypothesized relationships between ethical leadership and the three mediating variables must be interpreted with caution due to same-source concerns. For example, it is possible that employees' evaluations of ethical leadership biased their ratings of perceptions of LMX, selfefficacy, and organizational identification. To address this potential limitation, we obtained performance evaluations from direct reports' supervisors. Nevertheless, future research should strive to measure all predictors and performance ideally from different sources or utilize manipulations or objective outcomes. 
Second, because our study is cross-sectional by design, we cannot infer causality. Indeed, it is possible that, for example, LMX could drive perceptions of ethical leadership as opposed to the causal order we predicted. Additionally, employing an experimental research design to address causality issues would be useful. For example, a lab study could aid in making causal claims for each of the specific mediators investigated in the present study.

Third, we measured employee performance with evaluations from supervisors. Because prior research has shown meta-analytically that objective performance and subjective performance ratings cannot be equated (Bommer, Johnson, Rich, Podsakoff, \& MacKenzie, 1995), we encourage future studies to replicate our findings using objective performance, such as sales or revenue growth. Further, given our research design, we were unable to have an objective measure of ethical leadership. However, we aggregated ethical leadership data to provide a more objective measure but manipulating ethical leadership in future work could be useful.

Fourth, although we did examine three theoretically relevant mediators and test their effects simultaneously, other mechanisms could help explain the relationship between ethical leadership and employee performance. For example, Piccolo et al. (2010) found that task significance mediated this relationship. Future research should provide a more exhaustive test of different mediators including task significance, the mediators we assessed, as well as other potential mediators such as supervisor support, dedication, psychological safety, and cohesion.

Finally, aside from procedural justice, we did not control for other forms of related leadership theories. Future research could benefit by controlling for other styles of leadership that have been found to positively relate to ethical leadership such as transformational leadership (Bass \& Avolio, 1994) to examine whether ethical leadership explains additional unique variance (see Brown et al., 2005, Mayer et al., in press and Walumbwa and Schaubroeck, 2009, for examples of ethical leadership effects while controlling for related leadership styles).

Despite these potential limitations, the present study has some notable strengths worth highlighting. For example, we collected data from distinct sources which helped to reduce potential problems associated with common method bias (Podsakoff, MacKenzie, Lee, \& Podsakoff, 2003). We also controlled for procedural fairness to provide further evidence of the discriminant and incremental validity of ethical leadership.

In summary, despite the importance of ethical leadership and ethical behavior in organizations, research investigating the potential mechanisms through which ethical leadership influences effective performance has been lacking. This study makes an important contribution by examining how and why ethical leadership is more effective in enhancing employee performance by highlighting the importance of LMX, self-efficacy, and organizational identification. Thus, we provide a more complete picture on how to translate ethical leader behavior into follower action such as effective employee performance. We hope the present findings will 
stimulate further investigations into the underlying mechanisms and the conditions under which ethical leadership relates to various individual and group outcomes, including counterproductive behaviors. 


\section{Acknowledgments}

An earlier version of this article was presented at the 2010 annual meeting of the Academy of Management, Montreal, Canada. We are grateful to Russell Cropanzano and Marie Mitchell for their excellent suggestions on some aspects of this paper. We also thank Action Editor, Daan van Knippenberg and three anonymous reviewers for their insightful comments and suggestions. This research was supported in part by a grant from the National Science Foundation of China (NSFC Grant \#: 71032001). 
Table 1. Measurement model comparisons.

\begin{tabular}{|c|c|c|c|c|c|c|c|}
\hline Measurement models and structure & $x^{2}$ & df & $\Delta x^{2}$ & TLI & $\mathrm{CFI}$ & RMR & RMSEA \\
\hline $\begin{array}{l}\text { Six factor measurement model (PF, EL, LMX, SE, ID, } \\
\text { performance) }\end{array}$ & 79.34 & 62 & - & 0.99 & 0.99 & 0.01 & 0.04 \\
\hline $\begin{array}{l}\text { Five factor measurement model (PF and EL } \\
\text { indicators merged, LMX, SE, ID, performance) }\end{array}$ & 237.95 & 67 & $158.61^{*}$ & 0.85 & 0.89 & 0.05 & 0.11 \\
\hline $\begin{array}{l}\text { Five factor measurement model (EL and LMX } \\
\text { indicators merged, PF, SE, ID, performance) }\end{array}$ & 177.88 & 67 & $98.54^{*}$ & 0.88 & 0.9 & 0.05 & 0.1 \\
\hline $\begin{array}{l}4 \text { Five factor measurement model (EL and SE } \\
\text { indicators merged, PF, LMX, ID, performance) }\end{array}$ & 147.46 & 67 & $68.12^{*}$ & 0.9 & 0.91 & 0.05 & 0.08 \\
\hline $5 \begin{array}{l}\text { Five factor measurement model (EL and ID } \\
\text { indicators merged, PF, LMX, SE, performance) }\end{array}$ & 167.26 & 67 & $87.92^{*}$ & 0.9 & 0.91 & 0.05 & 0.09 \\
\hline $\begin{array}{l}\text { Five factor measurement model (LMX and SE } \\
\text { indicators merged, PF, EL, ID, performance) }\end{array}$ & 156.05 & 67 & $76.71^{*}$ & 0.9 & 0.91 & 0.05 & 0.09 \\
\hline $\begin{array}{l}7 \text { Five factor measurement model (LMX and ID } \\
\text { indicators merged, PF, EL, SE, performance) }\end{array}$ & 164.5 & 67 & $85.16^{*}$ & 0.89 & 0.9 & 0.05 & 0.09 \\
\hline $\begin{array}{l}8 \text { Five factor measurement model (SE and ID } \\
\text { indicators merged, PF, EL, LMX, performance) }\end{array}$ & 156.26 & 67 & $76.92^{*}$ & 0.9 & 0.91 & 0.05 & 0.09 \\
\hline $\begin{array}{l}\text { Note. } n=201 . P F=\text { procedural fairness, } E L=\text { ethical le } \\
\text { identification. The } \Delta x 2 \text { is in relation to Model } 1 .\end{array}$ & dership, $L$ & $x=$ leader & -mem & ange, $S E$ & $=$ self-effic & $c y, I D=$ or & zational \\
\hline${ }^{*} \mathrm{p}<01$ & & & & & & & \\
\hline
\end{tabular}


Table 2. Correlations among study variables.

\begin{tabular}{|c|c|c|c|c|c|c|c|c|}
\hline Variable & $\mathrm{M}$ & SD & 1 & 2 & 3 & 4 & 5 & 6 \\
\hline 1 Procedural fairness & 3.39 & 0.68 & 0.89 & & & & & \\
\hline 2 Ethical leadership & 4.13 & 0.47 & $.50^{* *}$ & 0.87 & & & & \\
\hline 3 Leader-member exchange & 3.9 & 0.52 & $.37^{* *}$ & $.48^{* *}$ & 0.88 & & & \\
\hline 4 Self-efficacy & 4.01 & 0.57 & $.16^{*}$ & $.38^{* *}$ & $.36^{* *}$ & 0.81 & & \\
\hline 5 Organizational identification & 3.97 & 0.53 & $.31^{* *}$ & $.36^{* *}$ & $.40^{* *}$ & $.34^{\star \star}$ & 0.84 & \\
\hline 6 Job performance & 3.42 & 0.75 & $.16^{*}$ & $.14^{*}$ & $.29^{* *}$ & $.18^{\star *}$ & $.20^{* *}$ & 0.92 \\
\hline \multicolumn{9}{|c|}{ Note. $n=201$. Internal consistency reliability (alpha) coefficients are reported in diagonal. } \\
\hline & & & & & & & & \\
\hline${ }^{\star} \mathrm{p}<.05$ (2-tailed). & & & & & & & & \\
\hline${ }^{* *} p<.01$ (2-tailed). & & & & & & & & \\
\hline
\end{tabular}


Table 3. Hierarchical linear modeling results: effects of ethical leadership on job performance. ${ }^{a}$

\begin{tabular}{|c|c|c|c|c|c|c|}
\hline Level and variable & Performance (M1) & LMX (M2) & SE (M3) & $\begin{array}{c}\text { Identification } \\
\text { (M4) }\end{array}$ & $\begin{array}{c}\text { Performance } \\
\text { (M5) }\end{array}$ & $\begin{array}{c}\text { Performance } \\
\text { (M6) }\end{array}$ \\
\hline \multicolumn{7}{|l|}{ Step 1} \\
\hline Intercept & $3.54(.11)^{\star \star}$ & & & & & \\
\hline Procedural fairness & $.18(.07)^{\star *}$ & & & & & \\
\hline Ethical leadership & $.15(.05)^{\star \star}$ & & & & & \\
\hline $\mathrm{R} 2$ & $.11^{\star \star}$ & & & & & \\
\hline \multicolumn{7}{|l|}{ Step 2} \\
\hline Intercept & & $3.91(.11)^{\star *}$ & $3.99(.14)^{\star *}$ & $3.91(.14)^{\star \star}$ & & \\
\hline Procedural fairness & & $.11(.05)^{*}$ & $.12(.07)$ & $.18(.06)^{\star *}$ & & \\
\hline Ethical leadership & & $.50(.08)^{\star \star}$ & $.47(.08)^{\star *}$ & $.37(.07)^{\star *}$ & & \\
\hline $\mathrm{R} 2$ & & $.25^{\star \star}$ & $.17^{\star \star}$ & $.19^{* \star}$ & & \\
\hline \multicolumn{7}{|l|}{ Step 3} \\
\hline Intercept & & & & & $3.92(.12)^{\star \star}$ & \\
\hline Leader-member exchange & & & & & $.21(.05)^{*}$ & \\
\hline Self-efficacy & & & & & $.23(.05)^{\star *}$ & \\
\hline Organizational identification & & & & & $.21(.05)^{\star *}$ & \\
\hline $\mathrm{R} 2$ & & & & & $.22^{\star \star}$ & \\
\hline \multicolumn{7}{|l|}{ Step 4} \\
\hline Intercept & & & & & & $3.92(.12)^{\star \star}$ \\
\hline Procedural fairness & & & & & & $.12(.08)$ \\
\hline Ethical leadership & & & & & & $.08(.07)$ \\
\hline Leader-member exchange & & & & & & $.16(.05)^{\star *}$ \\
\hline Self-efficacy & & & & & & $.18(.05)^{\star *}$ \\
\hline Organizational identification & & & & & & $.15(.05)^{\star *}$ \\
\hline $\mathrm{R} 2$ & & & & & & $.24^{\star *}$ \\
\hline \multicolumn{7}{|c|}{$\begin{array}{l}\text { a With the exception of ethical leadership (Level } 2 ; n=72) \text {, all other variables are Level } 1(n=201) . M=\text { model. } \\
\text { Values in parentheses are standard errors. }\end{array}$} \\
\hline${ }^{\star} p<.05$ & & & & & & \\
\hline${ }^{\star *} p<.01$ (2-tailed tests). & & & & & & \\
\hline
\end{tabular}




\section{References}

Ashforth, B. E., \& Mael, F. A. (1989). Social identity and the organization. Academy of Management Review, 14, $20-39$.

Avey, J. B., Palanski, M. E., \& Walumbwa, F. O. (2010). When leadership goes unnoticed: The moderating role of follower self-esteem on the relationship between ethical leadership and follower behavior. Journal of Business Ethics. doi:10.1007/s10551-010-0610-2.

Bandura, A. (1977). Social learning theory. Englewood Cliffs, NJ: Prentice-Hall.

Bandura, A. (1986). Social foundations of thought and action: A social cognitive theory. Englewood Cliffs, NJ: Prentice Hall.

Bandura, A. (1991). Social cognitive theory of self-regulation. Organizational Behavior and Human Decision Processes, 50, 248-281.

Bandura, A. (1997). Self-efficacy: The exercise of control. New York: Freeman. Bandura, A. (1999). Social cognitive theory: An agentic perspective. Asian Journal of Social Psychology, 2, 21-41.

Bandura, A., \& Locke, E. A. (2003). Negative self-efficacy and goal effects revisited. Journal of Applied Psychology, 88, 87-99.

Bass, B. M., \& Avolio, B. J. (1994). Improving organizational effectiveness through transformational leadership. Thousand Oaks, CA: Sage.

Bauer, T. N., Erdogan, B., Liden, R. C., \& Wayne, S. J. (2006). A longitudinal study of the moderating role of extraversion: Leader-member exchange, performance, and turnover during new executive development. Journal of Applied Psychology, 91, 298-310.

Blau, P. M. (1964). Exchange and power in social life. New York: Academic Press.

Bliese, P. D. (1998). Group size, ICC values, and group size correlations: A simulation. Organizational Research Methods, 1, 355-373.

Bliese, P. D. (2000). Within-group agreement, non-independence, and reliability: Implications for data aggregation and analysis. In K. J. Klein \& S. W. J. Kozlowski (Eds.), Multilevel theory, research and methods in organizations: Foundations, extensions, and new directions (pp. 349-381). San Francisco, CA: Jossey-Bass. 
Bliese, P. D., Halverson, R., \& Schriesheim, C. (2002). Benchmarking multilevel methods in leadership: The articles, the model, the data set. Leadership Quarterly, 13, 3-14.

Bommer, W. H., Johnson, J. L., Rich, G. A., Podsakoff, P. M., \& MacKenzie, S. B. (1995). On the interchangeability of objective and subjective measures of employee performance: A meta-analysis. Personnel Psychology, 48, 587-605.

Brislin, R. W. (1980). Translation and content analysis of oral and written materials. In H. C. Triandis \& J. W. Berry (Eds.), Handbook of cross-cultural psychology (pp. 389-444). Boston. MA: Allyn and Bacon.

Brown, M. E., \& Treviño, L. K. (2006a). Ethical leadership: A review and future directions. Leadership Quarterly, $17,595-616$.

Brown, M. E., \& Treviño, L. K. (2006b). Socialized charismatic leadership, values congruence, and deviance in work groups. Journal of Applied Psychology, 91, 954-962.

Brown, M. E., Treviño, L. K., \& Harrison, D. A. (2005). Ethical leadership: A social learning perspective for construct development and testing. Organizational Behavior and Human Decision Processes, 97, 117-134.

Chen, G., Casper, W. J., \& Cortina, J. M. (2001). The roles of self-efficacy and task complexity in the relationships among cognitive ability, conscientiousness, and work-related performance: A meta-analytic examination. Human Performance, 14, 209-230.

Chen, G., \& Kanfer, R. (2006). Toward a systems theory of motivated behavior in work teams. Research in Organizational Behavior, 27, 223-267.

Chen, G., \& Klimoski, R. J. (2003). The impact of expectations on newcomer performance in teams as mediated by work characteristics, social exchanges, and empowerment. Academy of Management Journal, 46, 591607.

Cole, N. D., \& Latham, G. P. (1997). Effects of training in procedural justice perceptions of disciplinary fairness by unionized employees and disciplinary subject matter experts. Journal of Applied Psychology, 82, 699705.

Colquitt, J. A. (2001). On the dimensionality of organizational justice: A construct validation of a measure. Journal of Applied Psychology, 86, 386-400.

Coyle-Shapiro, J. A. M., \& Conway, N. (2004). The employment relationship through the lens of social exchange. In J. A. M. Coyle-Shapiro, L. M. Shore, S. M. Taylor, \& L. Tetrick (Eds.), The employment relationship: Examining psychological and contextual perspectives (pp. 5-28). Oxford, UK: Oxford University Press. 
Cropanzano, R., \& Mitchell, M. S. (2005). Social exchange theory: An interdisciplinary review. Journal of Management, 31, 874-900.

De Cremer, D., Brebels, L., \& Sedikides, C. (2008). Being uncertain about what? Procedural fairness effects as a function of general uncertainty and belongingness uncertainty. Journal of Experimental Social Psychology, 44,1520-1525.

De Cremer, D., \& van Knippenberg, D. (2002). How do leaders promote cooperation? The effects of charisma and procedural fairness. Journal of Applied Psychology, 87, 858-866.

De Cremer, D., \& van Knippenberg, D. (2003). Cooperation with leaders in social dilemmas: On the effects of procedural fairness and outcome favorability in structural cooperation. Organizational Behavior and Human Decision Processes, 91, 1-11.

De Cremer, D., \& van Knippenberg, D. (2005). The effect of leader's self-sacrifice on cooperation: Trust and identification mediating charismatic leadership effects. Leadership and Organization Development Journal, 26, 355-369.

De Hoogh, A. H. B., \& Den Hartog, D. N. (2008). Ethical and despotic leadership, relationships with leader's social responsibility, top management team effectiveness and subordinates' optimism: A multi-method study. Leadership Quarterly, 19, 297-311.

Detert, J. R., \& Treviño, L. K. (2010). Speaking up to higher ups: How supervisor and skip-level leaders influence employee voice. Organization Science, 21, 249-270.

Detert, J. R., Treviño, L. K., Burris, E. R., \& Andiappan, M. (2007). Managerial modes of influence and counterproductivity in organizations: A longitudinal business unit-level investigation. Journal of Applied Psychology, 92, 993-1005.

Dienesch, R. M., \& Liden, R. C. (1986). Leader-member exchange model of leadership: A critique and further development. Academy of Management Review, 11, 618-634.

Dukerich, J. M., Golden, B. R., \& Shortell, S. M. (2002). Beauty is in the eye of the beholder: The impact of organizational identification, identity, and image on the cooperative behaviors of physicians. Administrative Science Quarterly, 47, 507-533.

Dutton, J. E., Dukerich, J. M., \& Harquail, C. V. (1994). Organizational images and member identification. Administrative Science Quarterly, 39, 239-263. 
Eden, D., \& Aviram, A. (1993). Self-efficacy training to speed reemployment: Helping people to help themselves. Journal of Applied Psychology, 78, 352-360.

Eden, D., \& Kinnar, J. (1991). Modeling Galatea: Boosting self-efficacy to increase volunteering. Journal of Applied Psychology, 76, 770-780.

Erdogan, B., Liden, R. C., \& Kraimer, M. L. (2006). Justice and leader-member exchange: The moderating role of organizational culture. Academy of Management Journal, 49, 395-406.

Gerstner, C. R., \& Day, D. V. (1997). Meta-analytic review of leader-member exchange theory: Correlates and construct issues. Journal of Applied Psychology, 82, 827-844.

Gouldner, A. W. (1960). The norm of reciprocity: A preliminary statement. American Sociological Review, 25, $161-178$.

Graen, G. B., \& Scandura, T. A. (1987). Toward a psychology of dyadic organizing. Research in Organizational Behavior, 9, 175-208.

Hogg, M. A. (2001). A social identity theory of leadership. Personality and Social Psychology Review, 5, 184200.

Hogg, M. A., Martin, R., Epitropaki, O., Mankad, A., Svensson, A., \& Weeden, K. (2005). Effective leadership in salient groups: Revisiting leader-member exchange theory from the perspective of the social identity theory of leadership. Personality and Social Psychology Bulletin, 31, 991-1004.

Hogg, M. A., \& van Knippenberg, D. (2003). Social identity and leadership processes in groups. Advances in Experimental Social Psychology, 35, 1-52.

James, L. R., Demaree, R. G., \& Wolf, G. (1984). Estimating within-group interrater-reliability with and without response bias. Journal of Applied Psychology, 69, 85-98.

Kenny, D. A., Kashy, D. A., \& Bolger, N. (1998). Data analysis in social psychology. In D. Gilbert, S. Fiske, \& G. Lindzey (Eds.). The handbook of social psychology (Vol. 1, pp. 233-265). Boston: McGraw-Hill.

Liden, R. C., Sparrowe, R. T., \& Wayne, S. J. (1997). Leader-member exchange theory: The past potential for the future. Research in Personnel and Human Resources Management, 15, 47-119.

Mael, F., \& Ashforth, B. E. (1992). Alumni and their alma mater: A partial test of the reformulated model of organizational identification. Journal of Organizational Behavior, 13, 103-123. 
Masterson, S. S., Lewis, K., Goldman, B. M., \& Taylor, M. S. (2000). Integrating justice and social exchange: The differing effects of fair procedures and treatment on work relationships. Academy of Management Journal, 43, 738-748.

Mayer, D. M., Aquino, K., Greenbaum, R. L., \& Kuenzi, M. (in press). Who displays ethical leadership and why does it matter: An examination of antecedents and consequences of ethical leadership. Academy of Management Journal.

Mayer, D. M., Kuenzi, M., Greenbaum, R., Bardes, M., \& Salvador, R. (2009). How low does ethical leadership flow? Test of a trickle-down model. Organizational Behavior and Human Decision Processes, 108, 1-13.

McAllister, D. J. (1995). Affect- and cognition-based trust as foundations for interpersonal cooperation in organizations. Academy of Management Journal, 38, 24-59.

Mitchell, M. S., \& Palmer, N. F. (2010). The managerial relevance of ethical efficacy. In M. Schminke (Ed.), Managerial ethics: Managing the psychology of morality (pp. 89-108). New York: Routledge.

Nahrgang, J. D., Morgeson, F. P., \& Ilies, R. (2009). The development of leader-member exchanges: Exploring how personality and performance influence leader and member relationships over time. Organizational Behavior and Human Decision Processes, 108, 256-266.

Piccolo, R. F., Greenbaum, R., Den Hartog, D. N., \& Folger, R. (2010). The relationship between ethical leadership and core job characteristics. Journal of Organizational Behavior, 31, 259-278.

Podsakoff, P. M., MacKenzie, S. B., Lee, J., \& Podsakoff, N. P. (2003). Common method biases in behavioral research: A critical review of the literature and recommended remedies. Journal of Applied Psychology, 88, 879-903.

Pratt, M. G., Rockmann, K. W., \& Kaufmann, J. B. (2006). Constructing professional identity: The role of work and identity learning cycles in the customization of identity among medical residents. Academy of Management Journal, 49, 235-262.

Raudenbush, S. W., \& Bryk, A. S. (2002). Hierarchical linear models: Applications and data analysis methods (2nd ed.). Thousand Oaks, CA: Sage.

Scandura, T. A., \& Graen, G. B. (1984). Moderating effects of initial leader-member exchange status on the effects of a leadership intervention. Journal of Applied Psychology, 69, 428-436.

Singelis, T. M. (1994). The measurement of independent and interdependent self-construals. Personality and Social Psychology Bulletin, 20, 580-591. 
Sluss, D. M., \& Ashforth, B. E. (2008). How relational and organizational identification converge: Processes and conditions. Organization Science, 19, 807-823.

Sluss, D. M., Klimchak, M., \& Holmes, J. J. (2008). Perceived organizational support as a mediator between relational exchange and organizational identification. Journal of Vocational Behavior, 73, 457-464.

Smidts, A., Pruyn, A., \& van Riel, C. B. M. (2001). The impact of employee communication and perceived external prestige on organizational identification. Academy of Management Journal, 49, 1051-1062.

Smith, H. J., Thomas, T. R., \& Tyler, T. R. (2006). Concrete construction employees: When does procedural fairness shape self-evaluations? Journal of Applied Social Psychology, 36, 644-663.

Sobel, M. E. (1982). Asymptotic confidence intervals for indirect effects in structural equation models. In S. Leinhardt (Ed.), Sociological methodology (pp. 290-312). Washington, DC: American Sociological Association.

Sparrowe, R. T., \& Liden, R. C. (1997). Process and structure in leader-member exchange. Academy of Management Review, 22, 522-552.

Spreitzer, G. M. (1995). Psychological empowerment in the workplace: Dimensions, measurement, and validation. Academy of Management Journal, 38, 1442-1465.

Stajkovic, A. D. (2006). Development of a core confidence higher-order construct. Journal of Applied Psychology, 91, 1208-1224.

Stajkovic, A. D., \& Luthans, F. (1998). Self-efficacy and work-related performance: A meta-analysis. Psychological Bulletin, 124, 240-261.

Tajfel, H. (1981). Human groups and social categories: Studies in social psychology. New York: Cambridge University Press.

Treviño, L. K., Brown, M. E., \& Hartman, L. P. (2003). A qualitative investigation of perceived executive ethical leadership: Perceptions from inside and outside the executive suite. Human Relations, 55, 5-37.

Treviño, L. K., Weaver, G. R., \& Reynolds, S. J. (2006). Behavioral ethics in organizations: A review. Journal of Management, 32, 951-990.

Tsui, A. S., Pearce, J. L., Porter, L. W., \& Tripoli, A. M. (1997). Alternative approaches to the employeeorganization relationship: Does investment in employees pay off? Academy of Management Journal, 40, 1089-1121. 
Tyler, T. R. (1997). The psychology of legitimacy: A relational perspective on voluntary deference to authorities. Personality and Social Psychology Review, 1, 323-345.

Tyler, T. R., \& Blader, S. L. (2000). Cooperation in groups: Procedural justice, social identity, and behavioral engagement. Philadelphia, PA: Psychology Press.

van Knippenberg, D. (2000). Work motivation and performance: A social identity perspective. Applied psychology, 49, 357-371.

van Knippenberg, D., \& De Cremer, D. (2008). Leadership and fairness: Taking stock and looking ahead. European Journal of Work and Organizational Psychology, 17, 173-179.

van Knippenberg, D., \& Hogg, M. A. (2001). Social identity processes in organizations. Group Processes and Intergroup Relations, 4, 185-189.

van Knippenberg, D., van Dick, R., \& Tavares, S. (2007). Social identity and social exchange: Identification, support, and withdrawal from the job. Journal of Applied Social Psychology, 37, 457-477.

van Knippenberg, D., van Knippenberg, B., De Cremer, D., \& Hogg, M. A. (2004). Leadership, self, and identity: A review and research agenda. Leadership Quarterly, 15, 825-856.

van Knippenberg, D., van Knippenberg, B., Monden, L., \& de Lima, F. (2002). Organizational identification after a merger: A social identity perspective. The British Journal of Social Psychology, 41, 233-252.

van Knippenberg, D., \& van Schie, E. C. M. (2000). Foci and correlates of organizational identification. Journal of Occupational and Organizational Psychology, 73, 137-147.

Walumbwa, F. O., Avolio, B. J., \& Zhu, W. (2008). How transformational leadership weaves its influence on individual job performance: The role of identification and efficacy beliefs. Personnel Psychology, 61, 793-825.

Walumbwa, F. O., Cropanzano, R., \& Hartnell, C. A. (2009). Organizational justice, voluntary learning behavior, and job performance: A test of the mediating effects of identification and leader-member exchange. Journal of Organizational Behavior, 30, 1103-1126.

Walumbwa, F. O., Cropanzano, R., \& Goldman, B. M. (in press). How leader-member exchange influences effective work behaviors: Social exchange and internal-external efficacy perspectives. Personnel Psychology. 
Walumbwa, F. O., \& Schaubroeck, J. (2009). Leader personality traits and employee voice behavior: Mediating roles of ethical leadership and work group psychological safety. Journal of Applied Psychology, 94, $1275-1286$.

Wang, H., Law, K. S., Hackett, R. D., Wang, D., \& Chen, Z. X. (2005). Leader-member exchange as a mediator of the relationship between transformational leadership and followers' performance and organizational citizenship behavior. Academy of Management Journal, 48, 420-432.

Wayne, S. J., \& Green, S. A. (1993). The effects of leader-member exchange on employee citizenship and impression management behavior. Human Relations, 46, 1431-1440.

Wayne, S. J., Shore, L. M., Bommer, W. H., \& Tetrick, L. E. (2002). The role of fair treatment and rewards in perceptions of organizational support and leader-member exchange. Journal of Applied Psychology, 87, 590-598.

Xie, J. L., Schaubroeck, J., \& Lam, S. S. K. (2008). Theories of job stress and the role of traditional values: A longitudinal study in China. Journal of Applied Psychology, 93, 831-848.

Zhu, W., May, D. R., \& Avolio, B. J. (2004). The impact of ethical leadership behavior on employee outcomes: The roles of psychological empowerment and authenticity. Journal of Leadership \& Organizational Studies, 11, 16-26. 